\title{
Microbiology (Endobacteriology) of Fruit and Vegetable Crops: An Expanded and Continuing Study
}

\author{
Jack R. Edelman ${ }^{1, ~ *, ~ Y u e ~ J . ~ L i n ~}{ }^{2}$ \\ ${ }^{1}$ Department of Science, Borough of Manhattan Community College, City University of New York, New York, U.S.A. \\ ${ }^{2}$ Department of Biological Sciences, Saint John's University, Jamaica, New York, U.S. A.
}

Email address:

themadprofessor47@hotmail.com (J. R. Edelman)

\section{To cite this article:}

Jack R. Edelman, Yue J. Lin. Microbiology (Endobacteriology) of Fruit and Vegetable Crops: An Expanded and Continuing Study. International Journal of Nutrition and Food Sciences. Vol. 5, No. 2, 2016, pp. 95-104. doi: 10.11648/j.ijnfs.20160502.12

\begin{abstract}
Many commercial fruits and vegetables consumed regularly by the public were tested for the presence and identification of bacteria within their inner flesh/pulp. Our recent previous work has shown that many commercial fruits and vegetables contain various species of resident bacteria, a science we have termed 'endobacteriololgy'. Fruits and vegetables were thoroughly washed and their inner flesh was swabbed onto agar plates. Any colonies that appeared were sent to specialized laboratories for identification by DNA sequence analysis. While many fruits and vegetables contained an inner flesh that was sterile, many others were found to harbor various species of bacteria. Among these were blueberries, rhubarb, pineapple, artichokes, okra, celery, asparagus, figs, anise/fennel, white/Rainier cherries, coconuts, cardoon, turmeric, and others. Leafy vegetables produced particularly large numbers of bacterial colonies, such as radicchio, Boston lettuce, Iceberg lettuce, red and green cabbage, Brussels sprouts, endive, bok choy/pak choy/Chinese cabbage. The presence of these species may or may not imply that consumption of these crops, when uncooked or undercooked, are hazardous to human health, except, perhaps, under certain disease/health conditions.
\end{abstract}

Keywords: Bacteria, Fruits, Vegetables, Allergy, Nosocomial Infections, Appendicitis

\section{Introduction}

We recently examined numerous members of the cucumber (Cucurbitaceae) family and found numerous species of bacteria in many fruits, including cucumbers, pickled cucumbers, melons, cantaloupes, gourds, squash, and others (Edelman and Lin, 2011). These organisms were located on the fruit surfaces, especially on the netting on the rinds and on wound scars, and/or inside the edible flesh/pulp itself. The study of bacterial species found on the rinds/outer surfaces/netting were referred to as "topobacteriology", while species found in the inner flesh/pulp was referred to as "endobacteriology" (Edelman and Lin, 2011).

In a subsequent study using numerous root crops, we identified species of bacteria endemic to numerous root crops, tubers, corms, and bulbs, such as Jerusalem artichokes, various radishes, horse radish, onions, celeriac/root celery, yucca/cassava, lotus root, water chestnuts, leeks, root parsley, jicama, edible burdock roots and others (Edelman and Lin, 2014). These bacteria seem to be endemic to these crops, and were found in the inner flesh/pulp of the roots (endobacteria); we did not examine the root outer surfaces for the presence of bacteria (topobacteriology) because these crops grow in the soil, and would be expected to harbor numerous bacteria on their surfaces which would be difficult to wash away. Our concern was to see if the inner flesh of the roots themselves harbor endemic bacteria since these parts of the crop are eaten directly and in all practicality cannot be washed out. Many of these root crops are eaten raw or uncooked or undercooked, which at least potentially might pose a health hazard to the public who consume such foods.

Aside from studying the presence of bacteria endemic to the inner fleas/pulp of the Cucurbitaceae and root crops, we decided to continue and expand this study to a variety of other fruits and vegetables that we did not previously test. The results of that study are currently presented in this report.

\section{Material and Methods}

Samples of fruits and vegetables (at least five specimens of each crop) to be tested for the presence of bacteria were purchased in local markets. Crops were washed well several 
times in soapy water and allowed to air dry. Incisions were made using sterilized knives and sterile cotton tip applicators were inserted into the inner flesh/pulp, and then swabbed onto agar plates containing tryptic soy agar. Plates were then incubated for 48 hours at $37 \mathrm{C}$ and examined for the presence of bacterial colonies. Plates that contained colonies were shipped to a microbial identification laboratory for identification by DNA sequence analysis (Accuratus Lab Services, 104 Gold Street, Agawam, Massachusetts, 01001, U.S.A.), (www.accuratuslabs.com).

Crops testing positive for the presence of bacteria in their inner flesh/pulp (endobacteria) were subjected to repeated testing to ascertain that there were no false-positive results. This was the same protocol that we used in our recent previous studies (Edelman and Lin, 2014).

\section{Results and Discussion}

While many fruits and vegetables tested were found to be sterile/free of endemic bacteria (endobacteria) there were also numerous crops indeed found to contain endemic bacteria. This was especially true of leafy vegetables, such as cabbage, lettuce, Brussels sprouts, radicchio, and artichokes, bok choy/pak choy, and stem/stalk vegetables (celery, rhubarb, asparagus, cardoon). Interestingly, certain other crops were also found to harbor endobacteria, such as blueberries, coconuts, pineapples, white/yellow (Rainier) cherries and figs. Results are shown in Table 1.

Table 1. Fruits and Vegetables containing endemic bacterial species in their inner flesh/pulp.

\begin{tabular}{|c|c|}
\hline Fruit/Vegetable: & Bacterial Species Present: \\
\hline \multicolumn{2}{|l|}{ Fennel } \\
\hline (Foeniculum vulgare) & Pseudomonas fulva \\
\hline \multicolumn{2}{|l|}{ Radicchio/Italian Chicory } \\
\hline \multirow[t]{2}{*}{ (Cichorium intybus) } & Pantoea ananatis \\
\hline & Pseudomonas tolaasii \\
\hline \multicolumn{2}{|l|}{ Boston Lettuce } \\
\hline \multirow[t]{2}{*}{ (Lactuca sativa) } & Pseudomonas fragi \\
\hline & Pseudomonas fluorescens \\
\hline \multicolumn{2}{|l|}{ Iceberg Lettuce } \\
\hline \multirow[t]{3}{*}{ (Lactuca sativa) } & Microbacterium sp. \\
\hline & Pseudomonas corrugata \\
\hline & Pseudomonas fluorescens \\
\hline \multicolumn{2}{|l|}{ Rhubarb } \\
\hline \multirow[t]{2}{*}{ (Rheum rhabarbarum) } & Obesumbacterium sp. \\
\hline & Microbacterium sp. \\
\hline \multicolumn{2}{|l|}{ Okra } \\
\hline (Abelmoschus esculentus) & Pantoea ananatis \\
\hline \multicolumn{2}{|l|}{ Globe Artichoke (heart) } \\
\hline \multirow[t]{3}{*}{ (Cynara scolymus) } & Pseudomonas brenneri/P.fluorescens \\
\hline & Plantibacter flavus \\
\hline & Pseudomonas marginalis \\
\hline \multicolumn{2}{|l|}{ Pineapple } \\
\hline (Ananas comossus) & Streptomyces cinereorectus \\
\hline \multicolumn{2}{|l|}{ Cabbage (Green) } \\
\hline \multirow[t]{2}{*}{ (Brassica oleracea) } & Pseudomonas fredericksbergensis \\
\hline & Erwinia persicina \\
\hline \multicolumn{2}{|l|}{ Cabbage (Red/Purple) } \\
\hline (Brassica oleracea) & Pantoea sp. \\
\hline \multicolumn{2}{|l|}{ Brussels Sprouts } \\
\hline \multirow[t]{2}{*}{ (Brassica oleracea) } & Arthrobacter sp. \\
\hline & Pseudomonas rhodesiae \\
\hline \multicolumn{2}{|l|}{ Endive } \\
\hline (Cichorium endivia) & Curtobacterium flaccumfaciens \\
\hline \multicolumn{2}{|l|}{ Blueberry } \\
\hline \multirow[t]{4}{*}{ (Vaccinium Corymbosum) } & Acidovorax temperans $(A T C C=49665)$ \\
\hline & Cellulosimicrobium sp. \\
\hline & Staphylococcus epidermidis \\
\hline & Staphylococcus hominis \\
\hline \multicolumn{2}{|l|}{ Celery } \\
\hline \multirow[t]{4}{*}{ (Apium graveolens) } & Microbacterium sp. \\
\hline & Pseudomonas corrugata \\
\hline & Labrys sp. \\
\hline & Staphylococcus hominis \\
\hline \multirow{3}{*}{$\begin{array}{l}\text { Asparagus } \\
\text { (Asparagus officinalis) }\end{array}$} & \\
\hline & Nesterenkonia sp. \\
\hline & Bacillus cereus \\
\hline
\end{tabular}




\begin{tabular}{|c|c|}
\hline Fruit/Vegetable: & Bacterial Species Present: \\
\hline \multicolumn{2}{|l|}{ White/Yellow Cherry/Rainier Cherry } \\
\hline \multirow[t]{2}{*}{ (Prunus avium Var. Bing $X$ Van) } & Bacillus atrophaeus \\
\hline & Bacillus altitudinis \\
\hline \multicolumn{2}{|c|}{ Pak Choy/Bok Choy/Chinese Cabbage } \\
\hline \multirow[t]{4}{*}{ (Brassica rapa chinensis) } & Metschnikowia pulcherrima \\
\hline & Curtobacterium sp. \\
\hline & Enterobacter amnigenus \\
\hline & Pseudomonas extremorientalis \\
\hline \multicolumn{2}{|l|}{ Fig/Common Fig } \\
\hline \multirow[t]{4}{*}{ (Ficus carica) } & Serratia marcescens \\
\hline & Serratia ficaria \\
\hline & Bacillus altitudinis \\
\hline & Staphylococcus saprophyticus \\
\hline \multicolumn{2}{|l|}{ Coconut } \\
\hline \multirow[t]{3}{*}{ (Cocos nucifera) } & Botryosphaeria rhodina \\
\hline & Tsukamurella sp. \\
\hline & Streptomyces albidoflavus \\
\hline \multicolumn{2}{|l|}{ Cardoon } \\
\hline \multirow[t]{3}{*}{ (Cynara cardunculus) } & Pseudomonas straminea \\
\hline & Pantoea agglomerans $\mathrm{ATCC}=27155$ \\
\hline & Acinetobacter calcoaceticus \\
\hline \multirow{4}{*}{$\begin{array}{l}\text { Breadfruit } \\
\text { (Artocarpus altilis) }\end{array}$} & \\
\hline & Pantoea agglomerans \\
\hline & Pectobacterium sp. \\
\hline & KIebsiella oxytoca \\
\hline \multicolumn{2}{|l|}{ Turmeric (fresh rhizomes) } \\
\hline \multirow[t]{2}{*}{ (Curcuma longa) } & Pantoea sp. \\
\hline & Pseudomonas straminea \\
\hline & Arthrobacter sp. \\
\hline \multirow{2}{*}{\multicolumn{2}{|c|}{$\begin{array}{l}\text { Goji Berries/Wolfberries (dried, packaged) } \\
\text { (Lycium chinense) }\end{array}$}} \\
\hline & \\
\hline & Terribacillus saccharophilus \\
\hline \multicolumn{2}{|r|}{ E } \\
\hline \multirow[t]{4}{*}{ (Morus alba) } & Enterococcus faecalis \\
\hline & Escherichia coli \\
\hline & Enterobacter cowanii \\
\hline & Pseudomonas sp. \\
\hline \multicolumn{2}{|c|}{ Indian Bitter Melon (heavily warted variety) } \\
\hline (Momordica charantia) & Pseudomonas oryzihabitans \\
\hline \multicolumn{2}{|l|}{ Longan Fruit } \\
\hline \multirow[t]{3}{*}{ (Dimocarpus longan) } & Leuconostoc mesenteroides \\
\hline & Yeast: Candida carpophila (or) \\
\hline & Meyerozyma guilliermondii \\
\hline Delicious Monster & \\
\hline (Monstera deliciosa) & Bacillus megaterium \\
\hline & Microbacterium sp. \\
\hline Golden Beet & \\
\hline (Beta vulgaris) & Bacillus altitudinis \\
\hline & Bacillus megaterium \\
\hline Rambutan & \\
\hline (Nephilium lappaceum) & Staphylococcus epidermidis \\
\hline Sweet Corn & \\
\hline (Zea mays) & Enterobacter cowanii \\
\hline & Pantoea ananatis \\
\hline Galeux d'Eysines Squash/Pumpki & \\
\hline Peanut Pumpkin & \\
\hline (Cucurbita maxima) & Staphyloccus sciuri (rind, netting, \& pulp) \\
\hline & Microbacterium arborescens (in pulp) \\
\hline
\end{tabular}

While many fruits and vegetables were found to contain endemic bacteria (endobacteria) in their inner flesh pulp, as listed in Table 1, most were found to be sterile; their inner flesh/pulp was found to be free of bacteria. These crops are listed in Table 2 , below: 
Table 2. Fruits and Vegetables in Which the Inner Flesh/Pulp Was Sterile (no endobacteria present).

\begin{tabular}{|c|c|}
\hline Common Name: & Scientific Name: \\
\hline Plum & Prunus domesticus \\
\hline Star Fruit/Carambola & Averrhoa carambola \\
\hline Avocado (Haas variety) & Persea Americana \\
\hline Banana acuminate/M.balbisiana & Musa \\
\hline Plantain & Musa X paradisiaea \\
\hline Persimmon (Fuyu/Sharon) & Diospyros kaki \\
\hline Tomatillo & Physalis philadelphica \\
\hline Tomato & Solanum lycopersicum \\
\hline Kiwi Fruit & Actinidia deliciosa \\
\hline Strawberry & Fragaria $X$ ananassa \\
\hline Aloe & Aloe vera \\
\hline Durian Fruit & Durio ibethinus \\
\hline \multicolumn{2}{|l|}{ Quenepas/Spanish Lime/ } \\
\hline \multicolumn{2}{|l|}{ Genip/Guinep/Genipe/Mamon/ } \\
\hline Mamoncillo/Limoncillo & Melicoccus bijugatus \\
\hline Apricot & Prunus armeniaca \\
\hline Nectarine & Prunus persica \\
\hline \multicolumn{2}{|l|}{ Cucuzzi Squash/Italian } \\
\hline \multicolumn{2}{|l|}{ Edible Gourd/New Guinea Bean/ } \\
\hline Cucuzza/Bottle Gourd & Lagenaria siceraria \\
\hline Lychee & Litchi chinensus \\
\hline \multicolumn{2}{|l|}{ Prickly Pear Cactus (green and } \\
\hline Red varieties) & Opuntia ficus-indica \\
\hline Fonzy Melon & Cucumis melo var. Fonzy \\
\hline Eggplant & Solanum melongena \\
\hline Dragon Fruit/Pitaya & Hylocereus undatus \\
\hline Bell Pepper (various colors) & Capsicum аппиит \\
\hline Grapefruit & Citrus $X$ paradise \\
\hline Lemon & Citrus limon \\
\hline Lime & Citrus aurantiifolia \\
\hline Orange (several varieties) & Citrus sinensis \\
\hline Apple (several varieties) & Malus domestica \\
\hline Pear (several varieties) & Pyrus communis \\
\hline Raspberry (red) & Rubus idaeus \\
\hline Blackberry & Rubus fruiticosis \\
\hline Guava & Psidium guajava \\
\hline Grape (several varieties) & Vitis labrusca \\
\hline Pomegranate & Punica granatum \\
\hline Quince & Cydonia oblonga \\
\hline Uglifruit & Citrus reticulata X paradisi \\
\hline Date & Phoenix dactylifera \\
\hline Cherry (Red/Purple/Bing) & Prunus avium \\
\hline Chayote Squash & Sechium edule \\
\hline Cranberry & Vaccinium macrocarpon \\
\hline Tamarind & Tamarindus indica \\
\hline Cherimoya & Annona cherimola \\
\hline Sugar Cane & Saccharum officinarum \\
\hline Jujube/Chinese Date & Ziziphus jujube \\
\hline Mamey fruit & Pouteria sapota \\
\hline Mangosteen fruit & Garcinia mangostana \\
\hline Passion Fruit/Granadilla & Passiflora edulis \\
\hline Turban Squash/Turk’s Turban & Cucurbita maxima 'Turban' \\
\hline $\begin{array}{l}\text { Cocoa beans (raw, unprocessed, } \\
\text { still inside the ripening pods) }\end{array}$ & Theobroma cacao *1 \\
\hline
\end{tabular}

*1: Found to be free of endobacteria, but several fungal/mold colonies grew on the agar plates. These were identified by DNA sequence analysis as Botryosphaeria rhodina a known fungal pathogen of Theobroma cacao trees and other tropical trees and plants.

While the majority of fruits and vegetables tested were found to have an inner pulp sterile/free of endemic bacteria, there were many in which the inner flesh/pulp contained endemic bacteria, as noted in Table 1. In most, if not all cases, leafy vegetables contained endemic bacteria, such as
Boston lettuce, iceberg lettuce, endive, Bok Choy/Pak Choy/Chinese cabbage, green cabbage, red/purple cabbage, Globe artichokes, Brussels sprouts, and radicchio. In addition, there were usually massive numbers of colonies appearing, rather than just a few. This may be due to the 
leaves being exposed to the soil during the growing season, as well as handling by humans during harvesting, shipping. and marketing. Bacteria which adhere to the leaves most likely stick to the surfaces and are not easily removable during washing. This is especially true of crops in which the leaves curl up over each other during the growing season in order to forms "heads", such as cabbage, Brussels sprouts, radicchio, and iceberg and Boston lettuce. Bacteria which have adhered to the leaves would be difficult if not impossible to wash off, especially after "heads" have formed. If such vegetables are boiled or otherwise cooked before consumption, these bacteria would most likely be destroyed, but some of these vegetables are eaten raw and/or placed in salads, so that many of the live endemic bacteria are eaten directly. The use of vinegar in salad dressings may destroy many/most of these organisms before actual consumption, especially if sufficient time is allowed to pass between application of salad dressing and consumption.

Interestingly, vegetables that grow in stem/stalk form also usually contained endemic bacteria, such as celery, rhubarb, asparagus, fennel, and cardoon. Since these vegetables were thoroughly washed before testing, the bacteria present were endemic to the inner flesh (endobacteria), rather than merely being contaminants on the outer surfaces (topobacteria). Interestingly, endobacteria were found previously to inhabit the roots of celery, often eaten as celery root/celeriac (Edelman and Lin, 2011), but here we found them to inhabit the stalks as well.

Even more interesting was the finding that while the common red/purple/Bing cherries, (Prunus avium), were found to be free of endobacteria, (Table 2), the white/yellow/Rainier cherries were found to contain endemic bacteria (Table 1). This may indicate that the phytopigments present in the red/purple/Bing cherries have antibacterial activity, while the absence/reduced amounts of these pigments in the white/yellow/Rainier cherries may explain the presence of endemic bacteria.

Another interesting finding was the presence of endemic bacteria in the inner flesh/pulp of pineapples, Ananas comossus. The bacterial species found was Streptomyces cinereorectus (Table 1), however, they were found in most but not all pineapples tested. Some pineapples tested were found to have a sterile inner flesh/pulp. However, when they were indeed present in a pineapple, they were present in very large numbers, rather than merely a few colonies. We speculate that these bacteria may enter the fruit through the crown during the growing season by rain splatter from the soil, and wind and insects.

It is of interest, also, that the common fig, Ficus carica, also contained several species of endemic bacteria in the inner flesh/pulp (Table 1). The specimens tested were freshly picked figs rather than dried figs, and even though the fruits were thoroughly washed with soapy water, there is a possibility that some bacterial species were introduced by human handling and packing/preparation for marketing. On the other hand, the bacterial species present may be completely endemic (endobacteria).
Another interesting finding was that the longan fruit, Dimocarpus longan, contained endobacteria, whereas the closely-related lychee fruit, Litchi chinensus, was found to be sterile.

The finding that blueberries (Vaccinium corymbosum) contain several species of endemic bacteria in their inner flesh/pulp (Table 1) was also surprising since blueberries are considered a very safe, health-promoting food, especially in recent years, due to their purported high antioxidant content. The presence of Staphylococcus epidermidis and S. hominis, usually found on human skin, may indicate that these species entered the inner flesh/pulp through human harvesting and packing, although, on the other hand, they may be endemic endobacteria present naturally.

Another interesting finding was that the inner flesh/pulp of the Fonzy melon (Cucumis melo var. Fonzy) was found to be sterile. This melon is actually a type of cantaloupe, and most cantaloupes were found to harbor endobacteria in our original study (Edelman and Lin, 2011). The lack of netting on the rind of this melon may explain the lack of endobacteria in its inner flesh/pulp.

Another interesting finding was that fresh growing rhizomes of turmeric (Curcuma longa) contained several endobacterial species, among which was of the genus Pantoea. In our previous study, fresh growing rhizomes of ginger (Zingiber officinale) also contained species of Pantoea as endemic bacteria, (Edelman and Lin, 2014), and these crops are closely related. This may infer that closelyrelated crops may share the same/similar species/genera of endemic bacteria in their inner flesh/pulp. Interestingly, both of these crops are purported to contain high levels of antioxidants and their consumption is advocated for human health. Dried, powdered turmeric is the source of the spice cumin, also purported to be a good source of antioxidants and advocated for human health.

Surprising as well was the finding that mulberries (Morus alba) contained several species of coliform bacteria, including E. coli. Mulberries are rarely, if ever, marketed commercially, most likely due to a short shelf life and because they are easily crushed by packaging and shipment. As a result, most people who consume mulberries hand-pick them from local trees. We suspect that the coliform endobacteria enter the fruit from birds that inhabit or perch in the trees. Bacteria may enter the fruit directly from bird defecation or are washed into the fruit from the tree branches by rain and wind. Due to the size and shape/conformation of the segments of the berries, even simple washing after harvesting may not be sufficient to remove the coliform bacteria.

Also noteworthy in this study is that the heavily warted Indian variety of bitter melon, (Momordica charantia), contained Pseudomonas oryzihabitans as an endemic species. In our previous study (Edelman and Lin, 2011), we had tested this crop for endobacteria but did not find this species present, but several other species were found instead (Stenotrophomonas maltophilia, Pseudomonas putida biotype A, and Salmonella choleraesuis salamae). This may indicate that endobacteria are transient in some/most/all fruits that 
contain surface warts; species may vary depending on location, soil type, climate conditions, and other natural and humancaused factors. It seems that crops that contain endemic bacteria most likely will always be found to contain bacteria, but the genera and species may vary depending on the location where the crops were grown. In concordance with the idea that warted species contain endobacteria, warted ornamental gourds were also found to harbor endobacteria in our previous study (Edelman and Lin, 2011). In further concordance with this idea was the finding that the heavily warted Galeux d'eysines pumpkin/Peanut pumpkin was also found to contain endobacteria, both inside the warts and the inner flesh/pulp. The warts on this pumpkin are very large and numerous, and have a netted, peanut shell resembling appearance, hence the nickname 'Peanut Pumpkin' (Figure 1). Figure 1 (top) shows the large thick netted warts on the surface of this fruit, while figure 1 (bottom) shows a close-up view of the warts, showing the netted, peanut-shell appearance. To date, all crops with surface warts have tested positive for endobacteria (Edelman and Lin, 2011, 2014, and this current study), including ornamental gourds, Chinese and Indian bitter melon, early summer crookneck squash, and galeux d'eysines pumpkin. This may indicate that the warts were somehow produced by endobacteria, although not all crops containing endobacteria contain warts. It is of interest that the netting on the warts strongly resembles netting on the surface of many melons, such as cantaloupes, and that the netting of these melons was found to harbor various species of bacteria (Edelman and Lin, 2011, 2014).

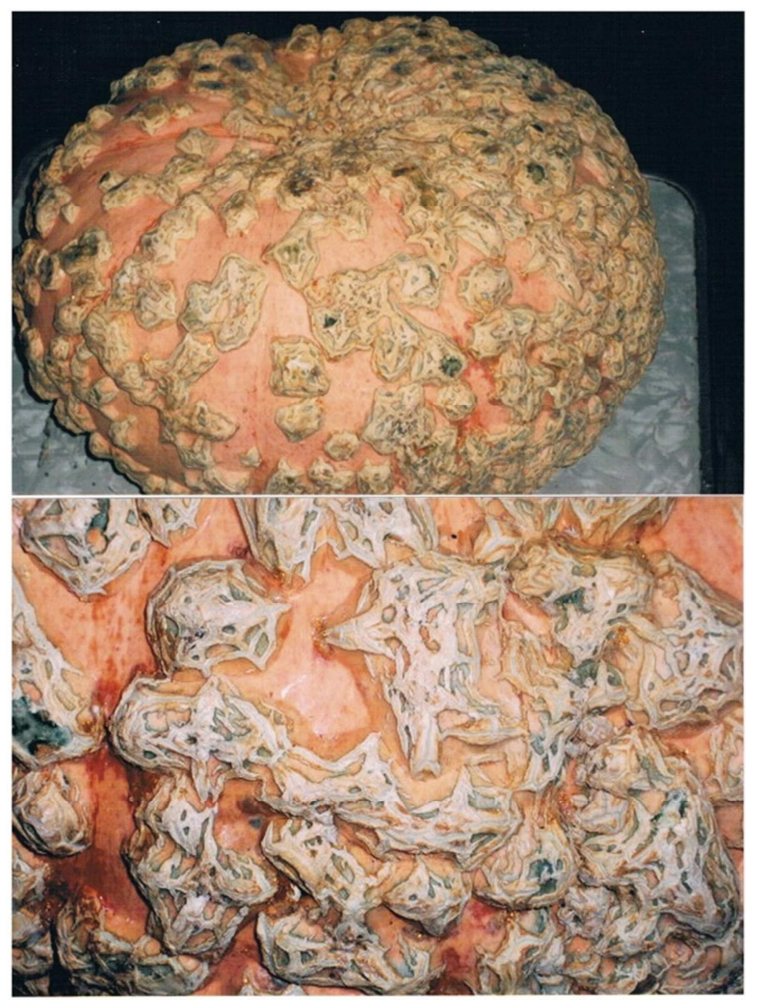

Figure 1. Galeux d'eysines pumpkin ('Peanut pumpkin') showing warted/netted peanut-shell-like surface. Endobacteria may be responsible for or involved in surface warts and netting.
Another interesting finding was that some crops that were found to be sterile/free of endobacteria in this study (Table 2) and in our previous studies (Edelman and Lin 2011, 2014) also had a long shelf life without decay and were able to propagate new plants. These include Chayote Squash (Sechium edule), potato tubers (Solanum tuberosum), garlic bulbs (Allium sativa) and tubers of Japanese Mountain Yam/Nagaimo. While these crops may shrink or shrivel in size due to dehydration/desiccation, they are generally resistant to rotting or decay even after long periods of time on the shelf or when refrigerated. These crops seem to be resistant to colonization by endobacteria and this resistance may account for their very long shelf life and their ability to propagate new/asexual progeny. We speculate that such crops might contain antimicrobial substances and should be examined as future prospective sources of antibiotics.

The fruits and vegetables listed in Table 1 may pose no health hazards at all for human consumption if they are well cooked (boiled, fried, baked, stewed), since the cooking process would most likely destroy the resident endobacteria. However, certain fruits and vegetables listed in Table 1 are only lightly cooked, eaten raw, or placed raw in salads, (such as lettuce, cabbage, figs, pineapple, fennel, radicchio, celery, endive, figs, blueberries, asparagus, white/yellow/Rainier cherries, and coconuts. These raw or lightly cooked fruits/vegetables might pose a health hazard, but probably only to those whose immune systems are compromised, those who are very young or very old, those in poor overall health, or to people who consume very large amounts of the particular fruit/vegetable in a short time period. This is similar to warnings listed on honey where it is advised not to give honey to babies less than one year of age due to Clostridium spores that may be present. It is also possible, in speculation, that consuming excess antacids or peptic proton inhibitor drugs might pose a health risk to those who consume large amounts of such foods by reducing the amount of hydrochloric acid production in the stomach. In speculation also, hospitals in which nosocomial infections are common might consider our findings when preparing patient meals. Our previous findings that melons with netted rinds, such as muskmelons and cantaloupes, contain various species of endobacteria (Edelman and Lin, 2011) in the inner flesh/pulp and on the rinds (topobacteria), prompted us to warn consumers to thoroughly wash the netted rinds with soapy water before consumption, and to avoid adding netted rinds to food processors when making purees and 'slurpies', 'smoothies' or juice mixtures (Edelman and Lin, 2014).

Interesting also was the finding that several species of bacteria were found in blueberries while Cranberries, a member of the same genus (Vaccinium) were found to be sterile. This may be due to different, more acidic substances found in cranberries that are either not found in blueberries or which are found in smaller amounts. Indeed, cranberry juice is advocated as a natural treatment for urinary infections today in both conventional and alternative medicine. Another 
possible explanation for the presence of bacteria in blueberries but not in cranberries might be the difference in harvesting, packaging and human handling of these crops. Streptococcus epidermidis and S. hominis may show up in blueberries from human handling.

The finding that endobacteria are found in Pineapples was interesting in that bacteria, Streptomyces cinereorectus were found in some but not in all pineapple specimens examined. Indeed, some pineapples were found to be sterile. Those pineapples in which this organism was found, however, showed dense colonial growth on the agar plates. We cannot explain this discrepancy in which this organism would be found in only some (but many) pineapple specimens. It would be expected that the acidity and presence of the protease bromelain would keep this fruit sterile, but obviously this was not found to be the case. We speculate here that people who are allergic to pineapple might not be allergic to the crop itself but rather might be allergic to the products of the endobacterial organism, $S$. cineorectus. This question needs to be investigated in future research. By extension of this idea, it is possible that persons allergic to any fruit or vegetable might actually be allergic to endobacterial species that are present, and/or their products which they secrete such as toxins or antibiotics, rather than to the crop itself. In coconuts, a similar phenomenon was seen, as most but not all contained Streptomyces albidoflavus. The presence of Streptomyces species in these crops might account for the mycotic or 'musty' odor often found both inside and on the surface of pineapples and coconuts.

It was interesting that goji berries also harbored endobacteria, since these berries are purported to be excellent sources of antioxidants and their consumption is highly recommended for human health. The goji berries tested in this study, however, were dried and packaged, so the possibility exists that contamination might have occurred during the drying and/or packaging process. We were unable to obtain freshly picked berries in order to answer this question. Of additional interest was that an organism found in gogi berries, Terribacillus saccharophilus, was found in field soil in Japan (An, et al., 2007) and the dried gogi berries used in this study were imported from the Orient/Far East.

Endobacteria may also play a role in the etiology of infections such as appendicitis, although this is merely speculation on our part. The causes of infections of the appendix are usually unknown, but since many crops do contain endemic endobacteria, as shown in this study, it is certainly possible that certain species might enter the appendix and cause infection. Obviously, more work is needed in this endeavor.

The present paper is not intended to create concern nor a 'health scare' amongst consumers of the crops in which we have identified endemic/endobacteria, because humans and other animals have been consuming these crops for thousands of years. The various species of endemic/endobacteria found in this study are symbionts which after consumption by humans and other animals may act as commensals, having no effects on the consumers, or possibly as mutualists, where both the symbiont and consumer benefit in some way. The primary goal of this report is to inform the scientific and medical community that many crops indeed harbor endemic bacteria (endobacteria) in their inner flesh/pulp, so that more studies might be undertaken to ascertain whether these symbionts pose any health risks at all or under special circumstances.

Most of the bacterial species found as endobacteria on the crops tested in this study (Table 1) are found endemically in the soil and bodies of water; some are plant pathogens, while others are found as commensals on human skin (Holt, 2000). They might have entered the plant tissues through physical and insect wounds or through human handling during cultivation, harvesting, and marketing, or possibly by adsorption/invasion through roots and conduction through the vascular system. In mere speculation, it is also possible that they might spread through cells vegetatively in plants that reproduce by asexual propagation, or possibly by genome integration of some sort (as yet unidentified) in the parental plants' germ cells.

While the presence of endobacteria in the foods found in this study do not necessarily imply that they pose any health risks, it should be noted that the medical literature indicates that many of these species have been implicated in infections in the past, although the source of infection may be unclear. Beau et al., (1999) reported blood infections by Nocardiopsis dassonvillei. Ahoyo et al., (2013) reported nosocomial infections by Staphylococcus sciuri; and infections by this species was also reported in piglets (Chen, et al., 2007). DeBaere et al., (2004) described bacteremia caused by Pseudomonas and Pantoea species--Pseudomonas extremorientalis and Pantoea ananatis. Otto (2009) described pathogenicity of Staphylococcus epidermidis. Funke et al., $(1995,1996)$ described infections caused by species of Microbacterium and Arthrobacter. Recent infections caused by Pseudomonads have also been reported: $P$. fulva---bloodstream infection (Seok et al., 2010); as well as acute meningitis (Almuzara, et al., 2010); (in this study $P$. fulva was found in fennel); P. fluorescens has also been found to cause bloodstream infections (Gershman et al., (2008). P. oryzihabitans has been found to cause pseudobacteremia and may be a cause of nosocomial infections (Woo et al. 2014). Raz et. al., (2005) reported pathogenicity of Staphylococcus saprophyticus, primarily urinary tract infections and cystitis. was originally isolated from a drinking water reservoir near Vladivostoc City, Russia (Ivanova, et al., (2002); in our present study this organism was found in Bok Choy/Chinese cabbage. Wareham et al., (2013) reported on bloodstream infections caused by Nesterenkonia species. Bottone (2010) noted that Bacillus cereus can cause food poisoning and sometimes fatal non-gastrointestinal tract infections. Serratia marcescens was recently implicated in nosocomial infections (Merkier, et al., 2013). Metschnikowia pulcherrima had previously been implicated in lung infectionms (Kennedy, et al., 1972). Curtobacterium 
species have sometimes been found to be pathogenic as well (Funke et al., 2005). Areas where fig trees are grown have been found to be associated with infections caused by Serratia ficaria (Anahory et al., 1998). Enterobacter amnigenus has caused infections of the lower limbs (Corti et al., 2009) as well as fatal septicemia after blood transfusions (Jan et al., 1999).

Three species found in coconuts in this study may also have medical implications; Botryosphaeria, a fungus, has been found to cause keratitis and vision loss (Bagyalakshmi et al., 2008). Tsukamorella species have been found to cause bacteremia in immunocompromised individuals (Schwartz, et al., 2002); Streptomyces albidoflavus has been found to cause skin infections (Cappelletti, et al., (2014).

Klebsiella oxytoca, found in this study in breadfruit, has been found to cause bacteremia in humans (Lin, et al., 1997). However, since this fruit is usually cooked, and rarely, if ever, eaten raw, the endobacteria present would most likely not be of any health risk.

Pantoea agglomerans, found in this and our previous studies (Edelman and Lin 2011, 2014) has been implicated in a variety of human infections, including those of the blood, urinary tract, bones, joints thorax, peritoneum and in abscesses (Cruz, et al., 2007).

Funke et al., (1996) found that various Arthrobacter species can cause infections in humans.

Bou, et al., (2008) studied nosocomial infections caused by Leuconostoc mesenteroides and indicated that they may have originated through parenteral nutrition. In the present study we have identified this organism in longan fruits, as noted in Table 1.

Kau et al., (2005) found that Enterococcus faecalis can case primarily urinary tract infections, but other organs/systems may also be infected. In the present study we have identified this organism in mulberries, as noted in Table 1.

Taj-Aldeen et al., (2014) noted that the yeast, Meyerozyma guillermondii, has been found to cause bloodstream infections. In the present study we have identified this organism in longan fruits. Candida carpophila, another yeast, was identified in the present study in longan fruits. While a literature search did not reveal any evidence of pathogenicity, it can be considered a potential pathogen since it a member of the Candida genus, which produces various yeast infections.

Duncan and Smith (2011) reported that Bacillus megaterium has produced skin infections with similar signs and symptoms of cutaneous anthrax infections. Mardenah and Soltan-Dallal (2014) found that Enterobacter cowanii, (a species found in this study in mulberries) is a potential pathogen often found in powdered milk.

On a final note, the finding that cocoa pods and beans harbor the fungus/mold Botryosphaeria rhodina prompts us to speculate that this organism might be responsible for allergies to chocolate/cocoa in some sensitive persons. It is of interest that we have also identified this organism in coconuts.

\section{Conclusions}

The current study conforms to our previous studies on the isolation and identification of bacterial species endemic to the inner flesh/pulp of many fruit and vegetable crops (Edelman and Lin 2011, 2014). We have coined the name 'endobacteriology' to this field of microbiology. Amongst fruits and vegetables found to contain endobacteria in this study are leafy vegetables such as lettuce, cabbage, bok choy/pak choy/chinese cabbage, artichokes, radicchio, Brussels sprouts, and endive. Other crops found to contain endobacteria were coconuts, pineapples, figs, white/yellow rainier cherries, blueberries, turmeric rhyzomes, okra, goji berries, breadfruit, mulberries, longan fruits, and stem/stalk vegetables such as rhubarb, celery, fennel, asparagus, and cardoon. Crops that are always cooked before consumption are probably safe/pose no health risks at all, but those that are eaten raw or only slightly cooked should be investigated further.

The finding that Indian bitter melon contained different species of endobacteria than those it was found to contain in our previous study indicates that the species may vary depending on the location and soil type/climatic conditions under which the crops were cultivated.

The finding that endobacteria are present in these crops does not necessarily imply that they pose health hazards due to human consumption, but rather that scientists and medical researchers should become aware that these symbionts are indeed present. Not all foods tested were positive for the presence of endobacteria; indeed, most were sterile. Foods found to be sterile might have implications in their possible antimicrobial potential. Foods found to harbor endobacteria should be researched further to study possible roles in food allergies and infections of the gastrointestinal tract including appendicitis (especially when antacids such as proton inhibitors are prescribed, and which, by lowering stomach acidity, may inhibit destruction of potentially pathogenic bacteria. In addition, we suggest that such foods be studied for possible roles in hospital (nosocomial) infections and food allergies. This report is not intended to produce any type of 'health scare' regarding the consumption of endobacteriapositive fruits and vegetables; its purpose is merely to inform the scientific and medical research communities that this new branch of microbiology ("endobacteriology") is worthy of further research. We are currently continuing this work to identify additional fruits and vegetables that harbor endobacteria.

\section{Note Added in Proof}

Fruits and vegetables that harbor endobacteria may also have implications for individuals that are immunocompromised, such as those persons undergoing chemotherapy or radiation therapy, in which exposure to or consumption of microorganisms may pose a health risk. 


\section{Acknowledgements}

We want to extend our gratitude to the following colleagues of the Science Department, Borough of Manhattan Community College, City university of New York, for their help in providing materials needed for this study: Ms. Carmen Rivera, Professor Owen Myers, Mr. Robert J. Bauer, Professor Christopher Thompson, and Professor Faisel Adem.

\section{References}

[1] Ahoyo, T. A., Yehouenou, P. E., Baba-moussa, L., Attolou, G. A., Boco, M., Dramane, K. K., Amihou, T., Staphylococcus sciuri outbreak at Tertiary hospital in Benin. J. Med. Microbiol. \& Diadnosis., 2013, 2: 126.

[2] Almuzara, M. N., Vazquez, M., Tanaka, N., Turco, M., Ramirez, M.S. Lopez, E.L., Pasteran, F., Rapoport, M., m Procopio, A., Vay, C.A., First case of a human infection due to Pseudomonas fulva, an environmental bacterium isolated from cerebrospinal fluid. 2010; J. Clin. Microbiol., 48: 660-664.

[3] An, S. Y., Asahara, M., Goto, K., Kasai, H., Yokota, A., Terribacillus saccharophilus gen. nov. sp. nov. and Terribacillus halophilus sp. nov. spore-forming bacteria isolated from field soil in Japan. Int'l. J. of Syst. and Evol. Microbiol. 2007; 57: 51-55.

[4] Anahory, T., Darbas, H., Ongaro, O., Jean-Pierre, H., Mion, P., Serratia ficaria: a misidentified or unidentified rare cause of human infections in fig tree culture zones. J. Clin. Microbiol. 1998; 36: 3266-3272.

[5] Bagyalakshmi, R., Therese, K.L., Prasanna, S., Madhavan, H.N., Newer emerging pathogens of ocular non-sporulating molds (NSM) identified by polymerase chain reaction (PCR)based DNA sequencing technique targeting internal transcribed spacer (ITS) region. Current eye Research; 2008; 33: 139-147.

[6] Beau, F., Bollet, C., Coton, T., Garnotel, E., Drancourt, M., Nocardiopsis dassonvillei blood isolate. 1999; J. Clin. Microbiol. 37: 3366-3368.

[7] Bottone, E.J., Bacillus cereus, a volatile human pathogen. Clin. Microbiol. Reviews, 2010; 23: 382-398.

[8] Bou, G., Saleta, J.L., Nieto, J.A.S., Tomas, M., Valdezate, S., Sousa, D., Lueiro, F., Villanueva, R., Pereira, M.J., Llinares, P. Nosocomial outbreaks caused by Leuconostoc mesenteroides subsp. mesenteroides. Emerging Infectious Diseases, 2008; 14: 968-971.

[9] Cappelletti, M.L., Livideanu, C.B., Kostantinou, M. P., Pauwels, C., Lourtet, J., Segonds, C., Cavalie, L., Rodriguez-Nava, V., Tournier, E., Marty, N., Grare, M., Paul, C., Infection cutanee primitive a Streptomyces albidoflavus. Annales de Dermatologie et de Venereologie, 2014; 141: S269.

[10] Chen, S., Wang, Y., Chen, F., Yang, H., Gan, M., Zheng, S. J., A highly pathogenic strain of Staphyloccus sciuri caused fatal exudative epidermitis in piglets, PLoS ONE, 2007; 2: e147.

[11] Corti, G., Mondanelli, N., Losco, M., Bartolini, L., Fontanelli, A., Paradisi, F., Post-traumatic infection of the lower limb caused by rare Enterobacteriaceae and Mucorales in a young healthy male. Int'1. J. Infect. Diseases, 2009; 13: e57-e60.
[12] Cruz, A. T., Cazacu, A. C., Allen, C. H., Pantoea agglomerans, a plant pathogen causing human disease. J. Clin. Microbiol., 2007; 45: 1989-1992.

[13] DeBaere, T., Verhlst, R., Labit, C., Verschaegen, G., Wauters, G., Claeys, G., Vaneechatte, M., Bacteremic infection with Pantoea ananatis. J. Clin. Microbiol., 2004, 42: 4393-4395.

[14] Duncan, K.O., Smith, T.L., Primary cutaneous infection with Bacillus megaterium mimicking cutaneous anthrax. J. American Acad. Dermatol. 2011; 65: e60-e61.

[15] Edelman, JR, Lin, YJ. Microbiology of melons, cucumbers, and squash (Cucurbitaceae) and related fruits. Int. J. of Food Science, Technology \& Nutrition. 2011; 5(1): 51-65.

[16] Edelman, JR, Lin, YJ. Microbiology of root crops, edible corms tubers, bulbs, and rhizomes: An endobacteriological study. Int. J. Nutrition and Food Sci. 2014; 3(2): 69-72. DOI: 10.11648/j.ijnfs.20140302.18

[17] Funke, G., Falsen, E., Barreau, C., Primary identification of Microbacterium spp. encountered in clinical specimens as CDC Cotyneform group A-4 and A-5 bacteria. J. Clin. Microbiol., 1995; 33: 188-192.

[18] Funke, G., Hutson, R.A., Bernard, K.A., Pfyffer, G.E., Wauters, G., Collins, M.D. Isolation of Arthrobacter spp. From clinical specimens and and description of Arthrobacter cumminsii sp. nov. and Arthrobacter woluwensis sp. nov. J. Clin. Microbiol., 1996; 34: 2356-2363.

[19] Funke, G., Aravena-Roman, M., Frodi, R., First description of Curtobacterium spp. Isolated from human clinical specimens. J. Clin. Microbiol. 2005; 43: 1032-1036.

[20] Gershman, M. D., Kenndey, D. J., Noble-Wang, J., Curi, K., Gullion, J., Kacica, M., Jensen, B., Pascoe, N., Saiman, L., McHale, J., Wilkins, M., Schoonmaker-Bopp, D., Clayton, J., Arduino, M., Srinivasan, A., Multistate outbreak of Pseudomonas fluorescens bloodstream infection after exposure to contaminated heparinzed saline flush prepared by a compounding pharmacy, Clin. Infect. Diseases, 2008; 47: 1372-1379.

[21] Holt, J. G. Bergey's Maniual of Determinative Bacteriology. Ninth Edition. 2000. Lippincott, Williams, \& Wilkins, Philadelphia, PA, USA.

[22] Ivanova, E. P., Gorshkova, N. M., Sawabe, T., Kalinovskaya, N. I., Lysenko, A. M., Zhukova, N. V., Kuznetsova, T. A., Mikhailov, W., Christen, R., Pseudomonas extremorientalis sp. nov., isolated from a drinking water reservoir. Int'l. J. Syst. Evol. Microbiol. 2002; 52: 2113-2120.

[23] Jan, D., Berlie, C., Babin, G., Septicemie fatale a Enterobacter amnigenus post-transfusionelle. Presse Med. 1999; 28: 965.

[24] Kau, A. L., Martin, S. M., Lyon, W., Hayes, E., Caparon, M. G., Hultgren, S. J., Enterococcus faecalis tropism for the kidneys in the urinary tract of $\mathrm{C} 57 \mathrm{BL} / 6 \mathrm{~J}$ mice. Infection and Immunity, 2005: 73: 2461-2468.

[25] Kennedy, W. P. U., Milne, L. J. R., Blyth, W., Crompton, G.K., Two unusual organisms, Aspergillus terreus and Metschnikowia pulcherrima, associated with the lung disease of ankylosing spondylitis. Thorax, 1972; 27: 604-610.

[26] Lin, R. D., Hsueh, P.R., Chang, S. C., Chen, Y. C., Hsieh, W. C., Luh, K. T., Bacteremia due to Klebsiella oxytoca: Clinical features of patients and antimicrobial susceptibilities of the isolates. Clin. Infect. Diseases, 1997; 24: 1217-1222. 
[27] Mardenah, J., Soltan-Dallal, M-M., Isolation and identification of E. cowanii from powdered infant formula in NICU and determination of antimicrobial susceptibility of isolates. Iran J. of Pediatrics, 2014; 24: 261-266.

[28] Merkier, A. K., Rodriguez, M. C., Togneri, A., Brengi, S., Osuna, C., Pichel, M., Cassini, M. H., Serratia marcescens Argentinian Collaborative Group, Centron, D., Outbreak of a cluster with epidemic behavior due to Serratia marcescens after colistin administration in a hospital setting. J. Clin. Microbiol. 2013; 51: 2295-2302.

[29] Otto, M. Staphylococcus epidermidis---the "accidental" pathogen. Nature Reviews; 2009; 7: 555-567.

[30] Raz, R., Colodner, R., Kunin, C. M., Who are you--Staphylococcus saprophyticus. Clin. Infect. Diseases, 2005; 40: 896-898.

[31] Schwartz, M. A., Collier, A. C., Carlson, L. C., Nguyen, T. T., Coyle, M. B., Tabet, S. R., Wallis, C. K., Kattar, M. M., Central venous catheter-related bacteremia due to
Tsukamorella species in the immunocompromised host: a case series and review of the literature. Clin. Infect. Diseases, 2002; 35: e72-77.

[32] Seok, Y., Shin, H., Lee, Y., Cho, I., Na, S., Yong, D., Jeong, S. H., Lee, K., First report of bloodstream infection caused by Pseudomonas fulva. J. Clin. Microbiol. 2010; 48: 2056-2057.

[33] Taj-Aldeen, S. J., AbdulWahab, A., Koleck, A., Deshmukh, A., Meis, J. F., Boekhout, T., Uncommon opportunistic yeast bloodstream infections from Qatar. 2014; Med. Mycol. 52: 552-556.

[34] Wareham, D., Phee, L., Homsey, M., P317 isolation and characterization of a novel Nesterenkonia species from a human bloodstream infection. Int'l. J. of Antimicrobial Agents, 2013; 42 (supplement 2): S141-S142.

[35] Woo, K-S, Choi, J-L., Kim, B-R., Kim, J-E., Kim, K-H., Kim, J-M., Han, J-Y., Outbreak of Pseudomonas oryzihabitans pseudobacteremia related to contaminated equipment in an emergency room of a tertiary hospital in Korea. 2014; Infection and Chemotherapy, 46: 42-44. 